\title{
As Políticas Públicas de Inclusão ao Ensino Superior: uma análise do contexto brasileiro nos últimos 20 anos $^{1}$
}

\section{Public Policies of Inclusion in Higher Education: an Analysis of the Brazilian Context in the Last 20 Years}

\author{
Rosane Beatris Mariano da Rocha Barcellos Terra ${ }^{1}$ \\ Guilherme Streit Carraro ${ }^{2}$ \\ Maria Paula da Rosa Ferreira ${ }^{1}$ \\ ${ }^{1}$ Universidade Franciscana, Santa Maria, RS, Brasil \\ ${ }^{2}$ Escola Paulista de Direito, São Paulo, SP, Brasil
}

Resumo: O trabalho analisa as políticas públicas ao ensino superior no País, tendo como principais objetivos demonstrar a evolução legislativa e dados quali-quantitativos acerca do acesso ao ensino superior por pretos e pardos. A pesquisa está amparada em método dedutivo. Os métodos de procedimento serão o histórico e o estatístico, inter-relacionando o estudo das políticas públicas de acesso ao ensino superior e aos dados governamentais e não governamentais. Na análise empírica, dados estatísticos serão necessários, especificando os atributos quali-quantificáveis dos dados recolhidos para uma compreensão em consonância com a construção teórica. Pode-se perceber, a título de resultados e de considerações finais, que ainda há muito para evoluir, porém será necessário implementar modificações significativas na tutela das ações afirmativas.

Palavras-chave: Ações Afirmativas. Educação. Ensino Superior.

Abstract: The paper analyzes the public policies for higher education in Brazil, with the main objectives of demonstrating legislative evolution and qualitative and quantitative data on access to higher education by blacks and browns. The research is supported by a deductive method. The methods of procedure will be historical and statistical, interrelating the study of public policies of access to higher education and governmental and nongovernmental data. In the empirical analysis, statistical data will be needed, specifying the quali-quantifiable attributes of the data collected for an understanding in line with theoretical construction. It can be perceived, by way of results and final considerations, that there is still a lot of evolution, but that significant changes in the protection of affirmative actions are being implemented.

Keywords: Affirmative Actions. Education. Higher Education.

\footnotetext{
${ }^{1}$ Trabalho derivado do Projeto "Das politicas públicas às políticas públicas de inclusão ao ensino superior: uma análise dos impactos e evolução histórica, no contexto brasileiro nos últimos 20 anos".
}

Recebido em: 03/01/2019

Revisado em: 10/09/2019

Aprovado em: 04/10/2019 


\section{Introdução}

É cediço que o papel do Estado assenta-se na necessidade de promover políticas para a unificação social. Dessa necessidade decorre a implementação legal de mecanismos para o fortalecimento de ações afirmativas, no intuito de inserir, na sociedade, pessoas em situação de exclusão. Desse modo, o tema em questão é inovador e está, bem como esteve, na pauta de prioridades da gestão federal por anos. Por isso, analisa-se a importância e o desenvolvimento das referidas políticas para o desenvolvimento social.

Objetiva-se, com esse trabalho, não só estudar as políticas públicas de acesso ao ensino superior nas instituições privadas, como meio de melhoria social, mas também demonstrar os impactos sociais no Brasil nas últimas duas décadas, por intermédio de pesquisa teórica e empírica. Nesse mote, o artigo se relaciona com as diretrizes dos cursos de Graduação, Pós-graduação Lato e Stricto Sensu da Instituição, pois está pautado em teorias jurídicas aplicadas na atualidade, mas também que serão fundamentais para o futuro do País.

Em termos metodológicos, está trabalhando com uma pesquisa qualitativa e quantitativa, eis que a compreensão dos dados estatísticos é feita de modo a estabelecer sua relação com a evolução legislativa brasileira. A pesquisa está amparada em método dedutivo, eis que apresenta assinalados, de forma bem marcantes, argumentos que se fundem ou atribuem certa probabilidade ao que está sendo primeiramente coletado e analisado e, posteriormente, analisado e concluído.

Por sua vez, os métodos de procedimento serão o histórico, o estatístico e o estudo de caso, tendo em vista a preocupação com a adequação e respeito ao estudo das políticas públicas, ao direito fundamental à educação e aos dados governamentais e não governamentais, respeitando-se, com respaldo acadêmico, sobre os resultados das ações afirmativas.

$\mathrm{Na}$ análise empírica, dados estatísticos serão necessários, especificando os atributos quali-quantificáveis dos dados recolhidos para uma compreensão em consonância com a construção teórica. Esta produção está centrada em documentação indireta, com coleta de dados e informa- 
ções secundárias, os quais demandarão uma análise estatística associada a uma interpretação qualitativa, com o objetivo de viabilizar o estabelecimento de categorias analíticas, a exibição adequada dos dados e a apresentação dos seus significados.

Desse modo, realizados os apontamentos pertinentes acima, cabe ressaltar que a escolha do tema em apreço, políticas públicas de acesso ao ensino superior, justifica-se, em especial, por ser uma temática que está conectada ao direito constitucional, embasado em direitos fundamentais: os direitos sociais à educação.

O trabalho está dividido em duas partes. Inicialmente é feita uma análise das ações afirmativas no Brasil enquanto política pública, sendo que se verificará a evolução no País. Ao depois, a partir dos dados colacionados na segunda parte do trabalho, verificam-se as razões e necessidades das políticas públicas de acesso ao ensino superior no Brasil, justamente em razão de dados quantitativos e que demonstram como se está em evolução ainda sobre a inclusão de diversos grupos excluídos de garantias básicas, como o acesso à educação.

Tais dados foram analisados de modo quanti-qualitativos, no intuito de demonstrar a situação brasileira, como se verá na sequência.

\section{Uma Análise Legislativa das Ações Afirmativas no Brasil como Política Pública}

Cabe analisar as ações afirmativas e sua previsão legislativa, antes de adentrar no tema educação. Inúmeros são os exemplos de legislações com ações afirmativas. Inicia-se destacando a Lei n. 7.668/1988, que instituiu a Fundação Cultural Palmares (FCP), vinculada ao Ministério da Cultura, cujo estatuto foi aprovado pelo Decreto n. 418, de 10 de janeiro de 1992. A FCP tem por fim preservar os valores culturais, sociais e econômicos da comunidade negra, que influenciaram na formação social do País, devendo atuar no território nacional.

A Lei que trata do regime jurídico dos servidores públicos civis da União, das autarquias e das fundações públicas federais, Lei n. 
$8.112 / 1990$, contém um dispositivo, qual seja, o artigo $5^{\circ}, \S 2^{\circ}$, que estabelece cotas de até $20 \%$ (vinte por cento) para os portadores de deficiência no serviço público civil da União. Na mesma esteira, o Decreto n. 3.298, de 20 de dezembro de 1999, que regulamenta a Lei n. 7.853/1989, dispondo acerca da Política Nacional para a Integração da Pessoa Portadora de Deficiência, estabelece no artigo 37, $\S 1^{\circ}$, que o percentual mínimo de reserva é de 5\% (cinco por cento). Essas legislações são fruto de determinação constitucional, pois o artigo 37, inciso VIII, determina a reserva dos cargos e empregos públicos para pessoas com deficiência.

Além das legislações citadas, o Brasil promulgou o Decreto n. 6.949 , de 25 de agosto de 2009, que ratificou a Convenção Internacional sobre os Direitos das Pessoas com Deficiência e seu Protocolo Facultativo, ambos assinados em Nova York, em 30 de março de 2007. Essa norma adentrou o ordenamento jurídico brasileiro com força de Emenda Constitucional, pois sua aprovação se deu em razão do quórum previsto no artigo $5^{\circ}, \S 3^{\circ}$ da Norma Fundamental.

No mesmo sentido, a Lei n. 8.213/1991, em seu artigo 93, concernente ao âmbito da iniciativa privada, a qual determina um aumento do percentual de contratação em caráter obrigatório de pessoas portadoras de capacidades especiais, levando-se em conta o número total de empregados, sendo que a empresa que tenha entre 100 (cem) e 201 (duzentos e um) empregados é obrigada a preencher $2 \%$ (dois por cento) dos seus cargos com beneficiários reabilitados ou pessoas com deficiência, habilitadas, sendo que o percentual aumenta gradativamente, conforme o número de empregados até o limite de 5\% (cinco por cento) dos seus cargos, nas empresas com mais de 1.000 empregados.

Nessa esteira de legislações que a visão de inclusão, desponta-se. Ainda, a Lei n. 8.666/1993, Lei das Licitações, em seu artigo 24, XX, prescreve a inexigibilidade de licitação para a contratação de associações filantrópicas de portadores de deficiências, para a prestação de serviços ou fornecimento de mão de obra, desde que a contratação esteja atrelada à compatibilidade e preço de mercado.

Outro exemplo de políticas públicas inclusivas, no sentido de prestigiar a cultura afrodescendente, vem representada pela Lei n. 9.125/1995, 
a qual instituiu o ano de 2005 como o ano Zumbi dos Palmares, por ser o ano do tricentenário de sua morte. O Ministério da Cultura, por força da referida Lei, ficou encarregado de planejar e coordenar a programação do ano comemorativo, sendo que a Empresa Brasileira de Correios e Telégrafos (ECT) foi autorizada a emitir selo em homenagem ao tricentenário da morte de Zumbi dos Palmares.

Em 20 de novembro de 1995, foi criado, pelo Governo Federal, o Grupo de Trabalho Interministerial (GTI) para a Valorização da População Negra, com o objetivo de sugerir ações e políticas de valorização da comunidade afrodescendente. Em 20 de março de 1996, foi instituído, no Ministério do Trabalho, o Grupo de Trabalho para a Eliminação da Discriminação no Emprego e na Ocupação (GTEDEO). Este Grupo, de composição tripartite, apresentava objetivos e finalidades voltados à definição de um programa de ações e à propositura de estratégias de combate à discriminação no emprego e na ocupação, como preconizado na Convenção 111, da Organização Internacional do Trabalho (OIT).

Em 1996, no Distrito Federal, tornou-se obrigatória a representação de todas as etnias nas propagandas institucionais, determinando a proporção de $54 \%$ de brancos, $40 \%$ de pardos, $5 \%$ de negros e $0,11 \%$ de índios. Já em 20 de novembro de 1997 (Dia Nacional de Valorização da Consciência Negra), houve a entrega solene, pelo Ministro Extraordinário da Política Fundiária Raul Jungmann, de títulos de propriedade aos integrantes das comunidades negras remanescentes dos quilombos. No ano seguinte, houve a promulgação da Lei n. 9.649/1998, a qual criou o Conselho Nacional de Combate à Discriminação (CNCD), no âmbito do Ministério da Justiça.

Na sequência, por meio da Portaria n. 1.740/99, o Ministério do Trabalho determinou a inclusão de dados informativos da raça e da cor dos empregados nos formulários da Relação Anual de Informações Sociais (RAIS) e no Cadastro Geral de Empregados e Desempregados (CAGED). Em junho de 2000, por meio da Portaria n. 604, o Ministério do Trabalho instituiu, no âmbito das Delegacias Regionais do Trabalho, os Núcleos de Promoção da Igualdade de Oportunidades e de Combate à Discriminação, 
encarregados de coordenar ações de combate à discriminação em matéria de emprego e profissão.

Em dezembro do mesmo ano, o Brasil participou da Pré-Conferência Regional das Américas, no Chile, e, logo em seguida, realizou várias Pré-Conferências Regionais em todo o País, organizadas pela Fundação Cultural Palmares e pelo Ministério da Cultura, com representantes do Movimento Negro, da sociedade civil, acadêmicos, cientistas sociais, parlamentares e gestores públicos, as quais desencadearam a iniciativa de criação de Políticas de Ações Afirmativas.

Na sequência, também, foi editada a Lei n. 10.172/2001, que aprovou o Plano Nacional de Educação, o qual estabelece a necessidade de políticas de inclusão de minorias étnicas. Em setembro daquele ano, o Ministério do Desenvolvimento Agrário, por meio da Portaria 202/2001, instituiu o Programa de Ações Afirmativas, Raça e Etnia. O referido Programa trata da reserva das vagas dos servidores contratados por concurso, dos cargos comissionados e dos empregados em empresas prestadoras de serviços ao ministério, estipulando o percentual de $20 \%$ (vinte por cento) das vagas para negros, $20 \%$ (vinte por cento) para mulheres e $5 \%$ (cinco por cento) para pessoas com deficiência.

Em 2001, ainda, o País participou em Durban, na África do Sul, da Conferência Mundial contra o Racismo, Discriminação Racial, Xenofobia e Intolerância Correlata. A partir de então, o governo brasileiro adotou um discurso mais incisivo quanto às políticas públicas de inclusão no Brasil (HERINGER, 2006).

Em 2002, o Brasil tornou-se signatário e fez o depósito da declaração facultativa prevista no art. 14 da Convenção Internacional sobre a Eliminação de Todas as Formas de Discriminação Racial, após o Congresso Nacional tê-lo aprovado, por meio do Decreto Legislativo 57, de 26 de abril de 2002. O Decreto Presidencial n. 4.228/02 instituiu o Programa Nacional de Ações Afirmativas e, em 13 de maio do mesmo período, foi lançado o Plano Nacional de Direitos Humanos II.

Nesse mesmo ano, o Ministério da Educação lançou o Programa Diversidade da Universidade (MP n. 63/2002) e a Universidade de Bra- 
sília (UNB) - estudou a possibilidade de reserva de $20 \%$ das vagas para estudantes negros. A proposta do Conselho Universitário previu a destinação de $20 \%$ das vagas no vestibular e no PAS (Programa de Avaliação Seriada) para negros.

A Secretaria de Políticas de Promoção da Igualdade Racial da Presidência da República foi criada pela Medida Provisória 111, de 21 de março de 2003, convertida na Lei n. 10.678, que surgiu com o intuito de reconhecer lutas históricas do Movimento Negro Brasileiro. Esta data é de suma importância, porque com ela se celebra o Dia Internacional pela Eliminação da Discriminação Racial, instituído em 1969, pela Organização das Nações Unidas (ONU), que faz lembrar o Massacre de Shaperville (ocorrido na África do Sul em 1960, no contexto do Apartheid), resultado de um protesto pacífico realizado por 20.000 negros contra a Lei do Passe, que consistia no porte de cadernetas de identificação, as quais especificavam os locais em que eles podiam circular. Nesse dia, o exército sul-africano atirou sobre a multidão, o que resultou em 69 mortos e 186 feridos.

Essa secretaria tem como finalidades a formulação, coordenação e articulação de políticas e diretrizes para a promoção da igualdade racial; a formulação, coordenação e avaliação das políticas públicas afirmativas de promoção da igualdade e da proteção dos direitos de indivíduos e grupos étnicos afetados por discriminação racial e demais formas de intolerância; a articulação, promoção e acompanhamento da execução dos programas de cooperação com organismos nacionais e internacionais que permitem a promoção da igualdade racial. Além destas, também tem, por fim, a coordenação e acompanhamento das políticas transversais de governo para a promoção da igualdade racial, o planejamento, coordenação da execução e avaliação do Programa Nacional de Ações Afirmativas e o acompanhamento da implementação de legislação de ação afirmativa e definição de ações públicas que visem ao cumprimento de acordos, convenções e outros instrumentos congêneres assinados pelo Brasil, nos aspectos relativos à promoção da igualdade e combate à discriminação racial ou étnica.

Em 2003 foi promulgada, também, a Lei n. 10.639, que tornou obrigatório o estudo da história e cultura afro-brasileira no ensino fundamen- 
tal e médio (HERINGER, 2006). No mesmo ano, foi instituída a Política Nacional de Promoção da Igualdade Racial pelo Decreto 4.886, de 20 de novembro de 2003.

Em 13 de maio do ano de 2005, foi lançado o Programa Nacional dos Direitos Humanos (PNDH) e, em 4 de junho de 2009, entrou em vigor o Plano Nacional de Promoção da Igualdade Racial (Planapir), aprovado pelo Decreto n. 6.872, que visa a promover a inclusão e igualdade racial e de remuneração entre diversos gêneros (mulher, negros, indígenas e quilombolas).

Dessa forma, é perceptível os inúmeros instrumentos legislativos que buscaram promover as mais diversas políticas de ação afirmativa, as quais foram elaboradas entre 2003 a 2010 . Nesse contexto, mais especificamente, em 20 de julho de 2010 promulgou-se a Lei n. 12.288, que instituiu o Estatuto da Igualdade Racial, a qual alterou a Lei n. 7.716/1989 (define os crimes resultantes de preconceito de raça ou de cor), a Lei n. 9.029/1995 (proíbe a exigência de atestados de gravidez e esterilização, e outras práticas discriminatórias, para efeitos admissionais ou de permanência da relação jurídica de trabalho, e dá outras providências), bem como a Lei n. 7.347/1985 (disciplina a ação civil pública de responsabilidade por danos causados ao meio-ambiente, ao consumidor, a bens e direitos de valor artístico, estético, histórico, turístico e paisagístico (VETADO) e dá outras providências), e Lei n. 10.778/2003 (estabelece a notificação compulsória, no território nacional, do caso de violência contra a mulher que for atendida em serviços de saúde públicos ou privados).

O Estatuto da Igualdade Racial destina-se a garantir à população negra a efetivação da igualdade de oportunidades, bem como a defesa dos direitos étnicos individuais, coletivos e difusos, visando ao combate à discriminação e às demais formas de intolerância étnica. Nas disposições preliminares do Estatuto, constam algumas definições importantes para o entendimento legal e social de termos, como: desigualdade de gênero e racial, população negra, políticas públicas e ações afirmativas.

Além disso, refere o Estatuto que para promover a participação da população negra, em condição de igualdade de oportunidade, na vida econômica, social, política e cultural do País, serão implementadas políticas 
públicas de desenvolvimento econômico e social, instituindo-se para tal fim o Sistema Nacional de Promoção da Igualdade Racial (Sinapir), cujo regulamento foi aprovado em 5 de novembro de 2013, pelo Decreto n. 8.136 .

Na mesma linha, em 2014, a Lei n. 12.990, determinou a reserva de $20 \%$ (vinte por cento) das vagas oferecidas nos concursos públicos para provimento de cargos efetivos e empregos públicos no âmbito da administração pública federal, das autarquias, das fundações públicas, das empresas públicas e das sociedades de economia mista controladas pela União, para negros, desde que existam três ou mais vagas. A vigência dessa política de inclusão é de dez anos contados da publicação da referida Lei.

Disso resulta, inexoravelmente, que há uma preocupação em igualizar o acesso da população que está alijada do ensino superior, eis que ainda existe uma má distribuição entre os brasileiros quanto ao nível de ensino, sendo que a atividade de prestação educacional deve objetivar eliminar possíveis discriminações, para não colaborar na fixação de desigualdades e preconceitos, que, por sua vez, ferem os objetivos fundamentais constitucionalmente garantidos.

Dessa feita, pode-se perceber que as políticas públicas de ações afirmativas esteve na pauta de discussão e ensejou diversas legislações na área, justamente com vistas a proteger o acesso à educação e melhores condições de vida.

\section{Apontamentos Quanti-Qualitativos acerca das Ações Afirma- tivas Brasileiras e o Ensino Superior}

A partir do analisado acerca da evolução legislativa brasileira, cabe identificar e criticamente compreender qualitativamente os dados quantitativos. O censo demográfico de 2014, conforme mostra o Quadro 1 atesta que parcela pequena da população parda e preta têm acesso ao ensino superior. Por tal razão, “[...] as propostas de ação afirmativa visando a ampliar o número de afrodescendentes (e também indígenas) no ensino 
superior ganharam corpo e se multiplicaram no Brasil” (HERINGER, 2006, p. 94).

Quadro 1 - Estudantes de 18 A 24 anos de idade, total e respectiva distribuição percentual, por nível de ensino frequentado e cor ou raça, com indicação do coeficiente de variação, segundo as grandes regiões $-2014^{2}$

\begin{tabular}{|c|c|c|c|c|c|c|c|c|c|c|}
\hline \multirow{4}{*}{$\begin{array}{c}\text { Grandes } \\
\text { Regiões }\end{array}$} & \multicolumn{10}{|c|}{ Estudantes de 18 a 24 anos de idade (1) } \\
\hline & \multirow{3}{*}{$\begin{array}{c}\text { Total } \\
(1000 \\
\text { pessoas })\end{array}$} & \multirow{3}{*}{$\begin{array}{l}\mathrm{CV} \\
(\%)\end{array}$} & \multicolumn{8}{|c|}{ Distribuição percentual, por nível de ensino frequentado (\%) } \\
\hline & & & \multicolumn{2}{|c|}{ Fundamental } & \multicolumn{2}{|c|}{ Médio } & \multicolumn{2}{|c|}{ Superior (2) } & \multicolumn{2}{|c|}{ Outros (3) } \\
\hline & & & \begin{tabular}{|c|} 
Per- \\
centual
\end{tabular} & $\begin{array}{l}\mathrm{CV} \\
(\%)\end{array}$ & \begin{tabular}{|c|} 
Per- \\
centual
\end{tabular} & \begin{tabular}{|l}
$\mathrm{CV}$ \\
$(\%)$
\end{tabular} & $\begin{array}{c}\text { Percen- } \\
\text { tual }\end{array}$ & $\begin{array}{l}\mathrm{CV} \\
(\%)\end{array}$ & Percentual & $\begin{array}{l}\mathrm{CV} \\
(\%)\end{array}$ \\
\hline \multicolumn{11}{|c|}{ Branca } \\
\hline Brasil & 3408 & 1,7 & 2,0 & 9,5 & 21,3 & 2,9 & 71,4 & 1,0 & 5,4 & 6,1 \\
\hline Norte & 181 & 4,7 & 6,5 & 18,2 & 33,0 & 6,6 & 53,6 & 4,4 & 6,9 & 16,0 \\
\hline Nordeste & 595 & 3,5 & 5,1 & 14,5 & 29,0 & 5,3 & 59,0 & 2,9 & 6,9 & 12,7 \\
\hline Sudeste & 1640 & 2,7 & 0,7 & 26,9 & 19,7 & 4,9 & 74,9 & 1,4 & 4,7 & $\overline{10,6}$ \\
\hline Sul & 753 & 3,9 & 1,2 & 24,3 & 17,0 & 6,7 & 76,3 & 1,6 & 5,5 & 11,1 \\
\hline Centro-Oeste & 238 & 4,7 & 2,0 & 28,9 & 17,5 & 9,8 & 76,3 & 2,5 & 4,2 & 20,0 \\
\hline \multicolumn{11}{|c|}{ Preta ou parda } \\
\hline Brasil & 3338 & 1,5 & 6,4 & 5,2 & 40,4 & 1,7 & 45,5 & 1,6 & 7,6 & 4,9 \\
\hline Norte & 502 & 2,9 & 9,8 & 9,1 & 45,8 & 3,4 & 35,8 & 3,7 & 8,5 & 10,0 \\
\hline Nordeste & 1309 & 2,5 & 8,9 & 7,1 & 44,2 & 2,5 & 39,6 & 3,0 & 7,2 & 7,8 \\
\hline Sudeste & 1046 & 3,0 & 3,3 & 14,8 & 36,5 & 3,7 & 51,9 & 2,8 & 8,2 & 9,3 \\
\hline Sul & 165 & 6,0 & 2,1 & 38,9 & 35,7 & 8,0 & 53,0 & 5,5 & 9,1 & 18,9 \\
\hline Centro-Oeste & 317 & 3,8 & 3,3 & 19,1 & 31,2 & 5,7 & 60,5 & 3,1 & 5,1 & 17,2 \\
\hline \multicolumn{3}{|c|}{$\begin{array}{l}\text { Fonte: IBGE. Pesquisa } \\
\text { Nacional por Amostra de } \\
\text { Domicílios 2014. } \\
\end{array}$} & & & & & & & & \\
\hline \multicolumn{8}{|c|}{$\begin{array}{c}\text { (1) Exclusive as pessoas de cor ou raça amarela e indígena. (2) } \\
\text { Inclui mestrado e doutorado. (3) Pré-vestibular, supletivo e } \\
\text { alfabetização de adultos. }\end{array}$} & & & \\
\hline
\end{tabular}

Fonte: Heringer (2006, p. 94)

Outro dado importante de ser destacado em relação ao gráfico acima, colacionado, é de que a população negra e parda tem certa vantagem numérica de frequência no ensino fundamental e médio em relação

${ }^{2}$ Os dados apresentados são de 2014, pois não há atualização governamental. O Sistema de Indicadores Sociais (SIS) foi atualizado, mas não analisa educação, apenas trabalho, rendimento e mobilidade. 
à população branca. Contudo, quando se trata do ensino superior, a porcentagem de frequência é extremamente baixa em relação aos brancos. Para modificação desse quadro, criaram-se diversos programas que visam a aumentar o acesso aos cursos superiores no Brasil, conforme se pode perceber na parte inicial do trabalho.

Antes, porém cabe observar que o Programa Universidade para Todos (Prouni), criado em 2004, e regulamentado pela Lei n. 11.096/2005, concede bolsas integrais e parciais em universidades privadas aos candidatos que tenham renda per capita de até três salários-mínimos e sejam oriundos da rede pública ou que tenham recebido bolsa integral para cursar o ensino médio em instituições privadas; os portadores de deficiência; e os professores da rede pública de ensino, que desejem cursar licenciatura, normal superior ou Pedagogia, cujo intuito seja a formação do magistério da educação básica. Nesse caso, independe a renda do candidato.

Atualmente, conforme mostra o Gráfico 1, o Prouni disponibilizou 306.726 (trezentas e seis mil, setecentos e vinte e seis) bolsas, somente no ano de 2014.

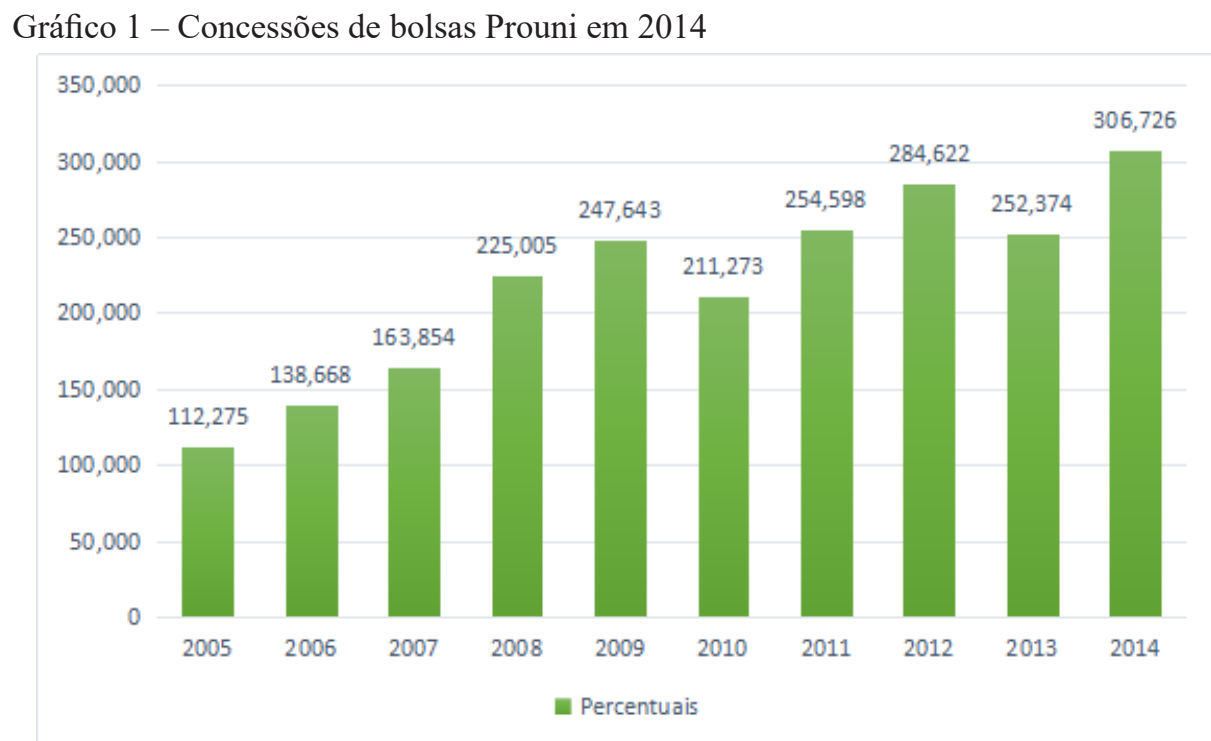

Fonte: Sisprouni (2014) 
Em relação às bolsas, no ano de 2014, foram concedidas 205.237 (duzentas e cinco mil, duzentas e trinta e sete) bolsas integrais e 101.489 (cento e um mil, quatrocentos e oitenta e nove) bolsas parciais, conforme mostra o Gráfico 2. Frisa-se que o último dado do governo em relação à distribuição de bolsas, informa que até o processo seletivo do segundo semestre de 2016, mais de 1,9 milhão de estudantes, sendo 70\% com bolsas integrais ${ }^{3}$.

Gráfico 2 - Concessão de bolsas integrais e parciais Prouni em 2014

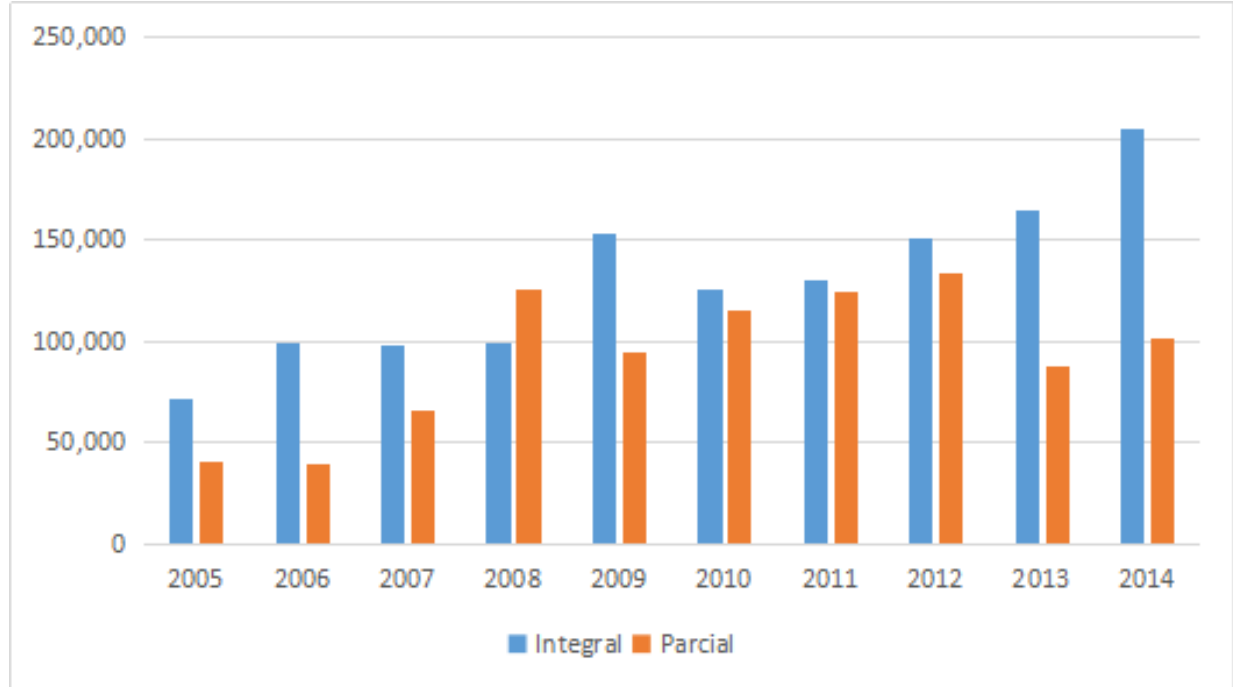

Fonte: Sisprouni (2014)

Acerca das bolsas ofertadas por processo seletivo, revela-se um aumento gradativo por processo seletivo, especialmente no ano de 2014, conforme mostra o Gráfico 3.

\footnotetext{
${ }^{3}$ Informação obtida em: http://prouniportal.mec.gov.br/o-programa.

${ }^{4}$ Os dados apresentados são de 2014, pois não há atualização governamental. O Sistema de Indicadores Sociais (SIS) foi atualizado, mas não analisa educação, apenas trabalho, rendimento e mobilidade.
} 
Gráfico 3 - Bolsas Prouni concedidas a negros e pardos (2004-2013)5

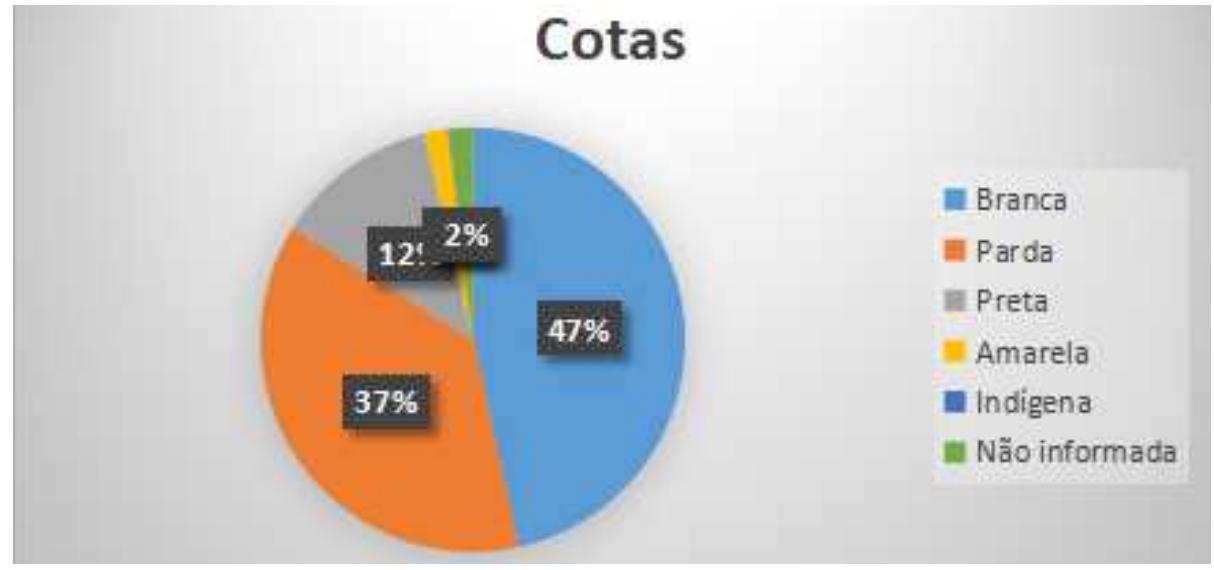

Fonte - Sisprouni (2013)

Durante o período de 2004 a 2013, as pessoas autodeclaradas negras receberam 159.053 (cento e cinquenta e nove mil, cinquenta e três) bolsas, o que significa $12,5 \%$ (doze inteiros e cinquenta centésimos por cento) dos beneficiados com o programa, conforme mostra o Gráfico 4.

Gráfico 4: Bolsas concedidas pelo Prouni no RS à população negra e parda ${ }^{6}$

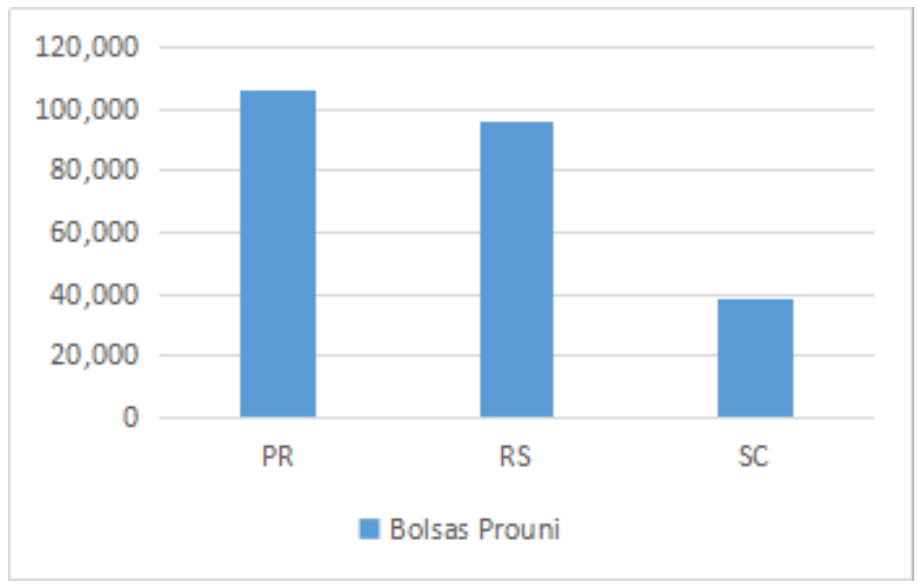

Fonte: Sisprouni (2013)

\footnotetext{
${ }^{5}$ Os dados apresentados são de 2013, pois não há atualização governamental.

${ }^{6}$ Os dados apresentados são de 2013, pois não há atualização governamental.
} 
Além de bolsas em instituições privadas, o Prouni também possui ações conjuntas que visam à acessibilidade no ingresso e permanência dos estudantes no ensino superior; cita-se como exemplo, a Bolsa Permanência e o Fundo de Financiamento Estudantil (Fies).

A Bolsa Permanência é um benefício para os estudantes que têm bolsa integral do Prouni, sendo que o valor máximo recebido equivale ao das bolsas de iniciação científica presentes na política federal. Já o Fies é um programa do Ministério da Educação criado para alunos que cursam graduação na educação superior em instituições não gratuitas, destina-se a financiar a graduação, na forma da Lei n. 10.260/2001. O financiamento é destinado aos estudantes matriculados em cursos superiores, desde que haja avaliação positiva nos processos conduzidos pelo Ministério da Educação. O Fies tem como taxa de juros 6,5\% a.a., carência de 18 meses e o período de amortização para três vezes o período de duração regular do curso + 12 meses. A partir de 2010, passou a ser Agente Operador do Programa o Fundo Nacional de Desenvolvimento da Educação (FNDE). Também, cabe frisar, que o percentual de financiamento é de até $100 \%$, sendo as inscrições realizadas em fluxo contínuo.

Todas essas políticas são parte da expansão de oferta do ensino superior, prevista no Plano Nacional de Educação de 2001 e ratificado no Plano Nacional de Educação vigente.

A redução das taxas de evasão e o aumento das vagas de ingresso, com a redução da ociosidade das vagas existentes, é diretriz do Reestruturação e Expansão das Universidades Federais (REUNI). O Programa também prevê que necessita haver a ampliação da mobilidade estudantil, reestruturação acadêmica, com atualização e reorganização dos cursos, além da diversificação dos cursos e a ampliação de políticas de inclusão e assistência estudantil. Ademais, tem-se como diretriz a articulação da graduação com a pós-graduação, bem como da educação superior com a educação básica.

Logo, pode-se perceber através dos dados e da evolução legislativa, que o País implementou diversas políticas afirmativas imperiosas para que o acesso ao ensino superior se perfectibilizasse, mas que ainda precisa evoluir. 


\section{Conclusão}

A partir da temática debatida na presente produção, destacou-se o papel do Estado na promoção de políticas públicas para a unificação social. Percebeu-se, nesse sentido, a necessidade do fortalecimento das ações afirmativas, com o propósito de garantir a inserção daqueles que se encontram sem situação de exclusão na sociedade.

O trabalho teve como tema uma análise das políticas públicas afirmativas no Brasil, especialmente nos últimos 20 anos. De início, teceram-se considerações legislativas, demonstrando a evolução legal das políticas públicas inclusivas no País, das mais diversas formas.

Na sequência, o trabalho apontou dados estatísticos e governamentais acerca do acesso ao ensino superior por pretos e pardos, demonstrando que os índices ainda são baixos e não representam uma paridade.

Almejou-se, com essa construção, contribuir para uma transformação social, uma vez que se dedicou a conhecer, estudar e interpretar, criticamente, a política pública de ingresso ao ensino superior no País.

Percebeu-se que as políticas públicas de ações afirmativas estiveram na pauta de discussão e ensejaram diversas legislações na área, justamente com vistas a proteger o acesso à educação em vista de melhores condições de vida.

Ainda, refletiu-se, através dos dados apresentados e da evolução legislativa, a implementação, no País, de diversas políticas afirmativas, imperiosas para que o acesso ao ensino superior se perfectibilizasse, o que, contudo, ainda merecem perpassar por determinados aperfeiçoamentos.

Dessa feita, em sede de considerações finais, se verificou certa evolução no tocante às ações afirmativas, todavia, aprimoramentos ainda devem ser realizados, tendo em vista que os índices ainda demonstram uma disparidade entre raças no Brasil.

Os dados apresentados, neste artigo, deixam claro que há desigualdades, em especial quando se trata de ensino superior, e que se precisa seguir a linha inclusiva. 
Importa referir que a mudança da política de governo interferiu na apresentação dos dados. Ademais, a previsão de término dessa política pública é 2024, quando se terá, acredita-se, indicativos que permitirão a verificação e contraposição dos gráficos expostos, bem como conclusões mais significativas acerca dos resultados finais na educação superior brasileira.

\section{Referências}

BRASIL. Constituição da República Federativa do Brasil. Presidência da República. 1988. Disponível em: http://www.planalto.gov.br/ccivil_03 /Constituição/Constitui\% C3\%A7ao.htm. Acesso em: 11 fev. 2018.

BRASIL. Decreto n. 3.298, de 20 de dezembro de 1999. Regulamenta a Lei n. 7.853, de 24 de outubro de 1989, dispõe sobre a Política Nacional para a Integração da Pessoa Portadora de Deficiência, consolida as normas de proteção, e dá outras providências. Disponível em: http:// www.planalto.gov.br/ccivil_03/decreto/d3298.htm. Acesso em: $11 \mathrm{fev}$. 2018.

BRASIL. Decreto n. 418, de 10 de janeiro de 1992. Aprova o Estatuto da Fundação Cultural Palmares - FCP, e dá outras providências. Disponível em: http://www2.camara.leg.br/legin/fed/decret/1992/decreto418-10-janeiro-1992-343081-publicacaooriginal-1-pe.html. Acesso em: 11 fev. 2018.

BRASIL. Lei n. 13.005, de 25 de junho de 2014. Aprova o Plano Nacional de Educação - PNE e dá outras providências. Disponível em: http://www.planalto.gov.br/ccivil_03/_Ato2011-2014/2014/Lei/L13005. htm. Acesso em: 11 fev. 2018.

BRASIL. Lei n. 7.668, de 22 de agosto de 1988. Autoriza o Poder Executivo a constituir a Fundação Cultural Palmares - FCP e dá outras providências. Disponível em: http://www.planalto.gov.br/ccivil_03/leis/ L7668.htm. Acesso em: 11 fev. 2018.

BRASIL. Lei n. 7.853, de 24 de outubro de 1989. Dispõe sobre o apoio às pessoas portadoras de deficiência, sua integração social, sobre 
a Coordenadoria Nacional para Integração da Pessoa Portadora de Deficiência - Corde, institui a tutela jurisdicional de interesses coletivos ou difusos dessas pessoas, disciplina a atuação do Ministério Público, define crimes, e dá outras providências. Disponível em: http://www. planalto.gov.br/ccivil_03/leis/17853.htm. Acesso em: 11 fev. 2018.

BRASIL. Lei n. 8.112, de 11 de dezembro de 1990. Dispõe sobre o regime jurídico dos servidores públicos civis da União, das autarquias e das fundações públicas federais. Disponível em: http://www.planalto.gov. br/ccivil_03/leis/18112cons.htm. Acesso em: 11 fev. 2018.

BRASIL. Lei n. 8.213, de 24 de julho de 1991. Dispõe sobre os Planos de Benefícios da Previdência Social e dá outras providências. Disponível em: http://www.planalto.gov.br/ccivil_03/leis/14024.htm. Acesso em: 11 fev. 2018.

BRASIL. Lei n. 8.666, de 21 de julho de 1993. Regulamenta o art. 37, inciso XXI, da Constituição Federal, institui normas para licitações e contratos da Administração Pública e dá outras providências. Disponível em: http://www.planalto.gov.br/ccivil_03/leis/18666cons.htm. Acesso em: 11 fev. 2018.

BUCCI, Maria Paula Dallari. Direito administrativo e políticas públicas. São Paulo: Saraiva, 2002.

BUCCI, Maria Paula Dallari. Fundamentos para uma teoria jurídica das políticas públicas. São Paulo: Saraiva, 2013.

BUCCI, Maria Paula Dallari. O conceito de políticas públicas em direito. In: BUCCI, Maria Paula Dallari. Políticas públicas: reflexões sobre o conceito jurídico. São Paulo: Saraiva. 2006. p. 143-161.

HERINGER, Rosana. Políticas de Promoção da Igualdade Racial no Brasil: um balanço de período 2001-2004. In: FERES JÚNIOR, João; ZONINSEIN, Jonas (org.). Ação afirmativa e universidade. Brasília: UnB, 2006. p. 17-35.

SCHMIDT, João Pedro. Para entender as políticas públicas: aspectos conceituais e metodológicos. In: LEAL, Rogério Gesta; REIS, Jorge 
Renato dos (org.). Direitos Sociais e Políticas Públicas: desafios contemporâneos. Edunisc: Santa Cruz do Sul, 2008. p. 2.307-2.333.

Rosane Beatris Mariano da Rocha Barcellos Terra

E-mail: rosanebterra@yahoo.com.br https://orcid.org/0000-0003-4682-2993

Doutora em Direito pela Universidade de Santa Cruz do Sul. Professora da Universidade Franciscana em Santa Maria, RS.

Endereço profissional: Universidade Franciscana, Rua Silva Jardim, n. 1.175, Santa Maria, RS. CEP: 97010-030.

\section{Guilherme Streit Carraro}

E-mails: gscarraro@gmail.com

Mestre em Direito pela Universidade de Marília. Mestrando em Direito pela Escola Paulista de Direito. Oficial Registrador de Cartório de Registro de Imóveis de Rancharia, SP.

Endereço profissional: Escola Paulista de Direito, Av. da Liberdade, n. 956, Liberdade, São Paulo, SP. CEP: 01502-001.

\section{Maria Paula da Rosa Ferreira}

E-mails: mariapauladarosa@hotmail.com

Mestre em Direito pela Universidade Federal de Santa Maria. Professora. Advogada.

Endereço profissional: Universidade Franciscana, Rua Silva Jardim, n. 1.175, Santa Maria, RS. CEP: 97010-030. 